\title{
EVALUATION OF LOCALIZED PAIN IN THE TRANSTIBIAL RESIDUAL LIMB
}

\author{
Kamiar Ghoseiri ${ }^{* 1}$, Mohammad Yusuf Rastkhadiv², Mostafa Allami ${ }^{3}$ \\ ${ }^{1}$ Department of Orthotics and Prosthetics, School of Rehabilitation Sciences, Hamadan University of Medical Sciences, Hamadan, \\ Iran. \\ ${ }^{2}$ Department of Occupational Therapy, School of Rehabilitation Sciences, Hamadan University of Medical Sciences, Hamadan, \\ Iran. \\ ${ }^{3}$ Janbazan Medical and Engineering Research Center (JMERC), Tehran, Iran.
}

* Email: k.ghoseiri@umsha.ac.ir

DOI: https://doi.org/10.33137/cpoj.v1i2.32028

\section{PURPOSE}

The socket is the main component of a prosthesis which surrounds the residual limb and transfers loads and motions between the residual limb and prosthesis. A misfit socket may lead to excessive stresses on the residual limb, pistoning of the prosthesis during walking, patient discomfort, pain, and skin damage. The quality of socket-skin interface directly affects quality of life, prosthesis use, and satisfaction from prosthesis in amputees. Pain is a devastating condition that prohibits prosthesis use ${ }^{1-4}$. The present study aimed to evaluate pain threshold and tolerance of the transtibial residual limb to improve its socket design and fit.

\section{METHODS}

Nineteen veterans with unilateral transtibial amputation participated in this cross sectional study. In supine position, the pain threshold and tolerance were evaluated at 12 locations on the residual limb with indentation method. Pain values at different locations were compared to each other. Correlations of pain values with demographic characteristics were explored.

\section{RESULTS}

Pain threshold and tolerance differed at all locations; however their difference was significant in mid-patellar tendon, medial tibial flare, and distal end of the tibia. The lowest and highest pain threshold and tolerance was distal end of the residual limb and mid-patellar tendon, respectively (Figure 1). There were no significant correlations between pain and demographic characteristics of participants except for the daily hours of prosthesis use.

\section{CONCLUSION}

Although the mid-patellar tendon and distal end of the residual limb were the best and worst load tolerant regions in transtibial amputees, due to the small difference between pain threshold and tolerance limits (range of 11-21 N/cm ${ }^{2}$ ), a small pain may be transformed to an intolerable pain, skin irritation and scar. Therefore, transtibial prosthetic sockets should be designed based on load tolerability of the residual limb.

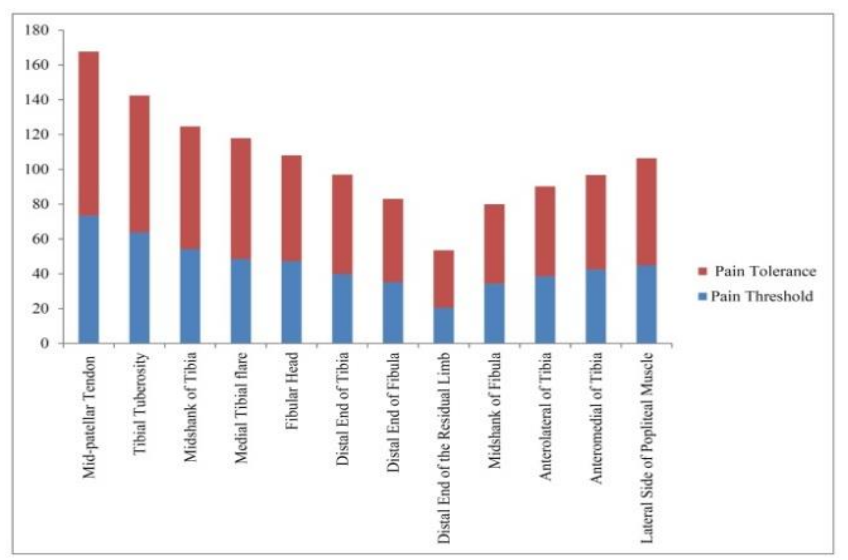

Figure 1: The results of pain threshold and tolerance at different locations on transtibial residual limb

\section{SIGNIFICANCE}

- Residual limb pain may be sourced from a misfit prosthetics socket.

- In transtibial residual limb, the lowest and highest pain threshold and tolerance was related to the distal end of the residual limb and mid-patellar tendon, respectively.

- Due to the small difference between pain threshold and tolerance limits, a small pain may be transformed to an intolerable pain.

- Transtibial socket design should be based on pain tolerability of the residual limb. 


\section{REFERENCES}

1. Dou P, et al. Pressure distribution at the stump/socket interface in transtibial amputees during walking on stairs, slope and non-flat road. Clin Biomech (Bristol, Avon); 21, 1067-73, 2006. DOI:10.1016/j.clinbiomech.2006.06.004

2. Zhang M \& Lee WC. Quantifying the regional load-bearing ability of trans-tibial stumps. Prosthet Orthot Int; 30, 25-34, 2006. DOI: $\underline{10.1080 / 03093640500468074}$

3. Fischer AA. Pressure tolerance over muscles and bones in normal subjects. Arch Phys Med Rehabil; 67, 406-9, 1986.

4. Lee WC, et al. Regional differences in pain threshold and tolerance of the transtibial residual limb: including the effects of age and interface material. Arch Phys Med Rehabil; 86, 6419, 2005. DOI:10.1016/j.apmr.2004.08.005

\section{DISCLOSURE}

The authors report no declarations of interest. However, the financial support of the research was done by the Janbazan Medical and Engineering Research Center (JMERC).

\section{ACKNOWLEDGMENTS}

The authors would like to thank the Veterans and Martyrs Affairs Foundation (VMAF) for their cooperation with the study. 